\title{
Effects of Huang Bai (Phellodendri Cortex) and Three Other Herbs on GnRH and GH Levels in GT1-7 and GH3 Cells
}

\author{
Sun Haeng Lee, ${ }^{1,2}$ Sung Chul Kwak, ${ }^{3}$ Dong Kwan Kim, ${ }^{3}$ Sang Woug Park, ${ }^{3}$ Hyun Soo Kim, \\ Young-Sik Kim, ${ }^{4}$ Donghun Lee, ${ }^{4}$ Ju Won Lee, ${ }^{5}$ Chang Gon Lee, ${ }^{5}$ Hae Kyung Lee, ${ }^{5}$ \\ Sung-Min Cho, ${ }^{1}$ Yu Jeong Shin, ${ }^{1}$ Jin Yong Lee, ${ }^{1,2}$ Hocheol Kim, ${ }^{4}$ and Gyu Tae Chang ${ }^{1,6}$ \\ ${ }^{1}$ Department of Clinical Korean Medicine, Graduate School, Kyung Hee University, Seoul 02447, Republic of Korea \\ ${ }^{2}$ Department of Pediatrics of Korean Medicine, Kyung Hee University Medical Center, Seoul 02447, Republic of Korea \\ ${ }^{3}$ Korea Institute of Science and Technology for Eastern Medicine (KISTEM), NeuMed Inc., Seoul 02440, Republic of Korea \\ ${ }^{4}$ Department of Herbal Pharmacology, College of Korean Medicine, Kyung Hee University, Seoul 02447, Republic of Korea \\ ${ }^{5}$ Department of East-West Medical Science, Graduate School of East-West Medical Science, Kyung Hee University, \\ Yongin 17104, Republic of Korea \\ ${ }^{6}$ Department of Pediatrics of Korean Medicine, Kyung Hee University Hospital at Gangdong, Seoul 05278, Republic of Korea
}

Correspondence should be addressed to Hocheol Kim; hckim@khu.ac.kr and Gyu Tae Chang; gtchang@khu.ac.kr

Received 8 October 2015; Accepted 16 December 2015

Academic Editor: Victor Kuete

Copyright (c) 2016 Sun Haeng Lee et al. This is an open access article distributed under the Creative Commons Attribution License, which permits unrestricted use, distribution, and reproduction in any medium, provided the original work is properly cited.

\begin{abstract}
The present study was to evaluate the effects of Huang Bai, Zhi Mu, Mai Ya, and Xia Ku Cao on hormone using the GT1-7 and GH3 cells. The GT1-7 and GH3 cell lines were incubated with DW; DMSO; and 30, 100, or $300 \mu \mathrm{g} / \mathrm{mL}$ of one of the four extract solutions in serum-free media for 24 hours. The MTT assay was performed to determine the cytotoxicity of the four herbs. The GT1-7 and GH3 cells were incubated in DW, estradiol (GT1-7 only), or noncytotoxic herb solutions in serum-free medium for 24 hours. A quantitative RT-PCR and western blot were performed to measure the GnRH expression in GT1-7 cells and GH expression in GH3 cells. Huang Bai, Zhi Mu, Xia Ku Cao, and Mai Ya inhibited the GnRH mRNA expression in GT1-7 cells, whereas Huang Bai enhanced GH mRNA expression in GH3 cells. Additionally, Xia Ku Cao inhibited GnRH protein expression in GT1-7 cells and Huang Bai promoted GH protein expression in GH3 cells. The findings suggest that Huang Bai can delay puberty by inhibiting $\mathrm{GnRH}$ synthesis in the hypothalamus while also accelerating growth by promoting GH synthesis and secretion in the pituitary.
\end{abstract}

\section{Introduction}

Some medicinal herbs and prescriptions have been reported to treat precocious puberty (PP). For example, in Taiwan, the Anemarrhena, Phellodendron, and Rehmannia Pill, containing Zhi Mu (Rhizoma Anemarrhenae), Huang Bai (Cortex Phellodendri), Di Huang (Radix Rehmanniae), Shan Zhu Yu (Fructus Corni), Shan Yao (Rhizoma Dioscoreae), Mu Dan Pi (Cortex Moutan), Fu Ling (Poria), and Ze Xie (Rhizoma Alismatis), are the most common prescription for PP (70.62\%), whereas Mai Ya (Fructus Hordei Germinatus; 20.11\%) and Xia Ku Cao (Spica Prunellae; 14.69\%) are the most common herbs that are used in combination with a PP prescription [1]. Additionally, in China, Zhi Mu (10.19\%), Di Huang (9.87\%), and Huang Bai $(8.92 \%)$ are the herbs most frequently used for yin deficiency with effulgent fire pattern PP, whereas Chai Hu (Radix Bupleuri; 9.09\%), Shao Yao (Radix Paeoniae; 6.82\%), and Dang Gui (Radix Angelicae Gigantis; 6.06\%) are the herbs most frequently used for depressed liver qi transforming into fire pattern PP [2].

The administration of the Nourishing "Yin" Removing "Fire" herbal mixture (Di Huang, Huang Bai, Zhi Mu, and others) to normal rats reportedly downregulates the expression of excitatory amino acid and gonadotropin-releasing hormone (GnRH) mRNA in the hypothalamus; folliclestimulating hormone (FSH), luteinizing hormone (LH), and GH mRNA in the hypophysis; and insulin-like growth factor(IGF-) I mRNA in the metaphysic, while upregulating the expression of inhibitory amino acid, neuropeptide Y (NPY), $\beta$-endorphin, and somatostatin mRNA in the hypothalamus 
$[3,4]$. Additionally, in a rat model of PP, this herbal mixture was shown to delay vaginal opening and to downregulate serum estradiol levels as well as the expression of Kiss-1 and GnRH mRNA in the hypothalamus $[5,6]$. The Zhizao granule, which contains Xia Ku Cao, Zhi Zi (Fructus Gardeniae), Chai Hu, Shao Yao, Gou Qi Zi (Fructus Lycii), Zhe Bei Mu (Bulbus Fritillariae), and Huang Qin (Radix Scutellariae), reduces serum FSH and LH levels in PP rats [7]. Similarly, a mixture containing Di Huang, Gui Ban (Plastrum Testudinis), Shan Yao, Shan Zhu Yu, Nu Zhen Zi (Fructus Ligustri Lucidi), Fu Ling, Ze Xie, Mu Dan Pi, and Zhi Mu reduces the ovarian index, uterine index, and ovarian corpus luteum occurrence rate [8].

However, single herbs that are used for the treatment of PP are rarely analyzed. Zi Cao (Radix Lithospermi) has been shown to independently reduce serum FSH, LH, and estradiol levels in rats [9] and to diminish vaginal opening, reduce ovary and uterus weights, and lower serum FSH, LH, and estradiol levels in mice [10]. Furthermore, this herb decreases uterine thickness and reduces serum FSH and LH levels while increasing the height of the femur growth plate in rabbits [10].

In the present study, the most frequently used and effective herbs for the treatment of PP, including Huang Bai, Zhi Mu, Xia Ku Cao, and Mai Ya, were assessed to determine their effect on inhibiting maturation and promoting growth by mRNA and protein analyses of GnRH and GH.

\section{Materials and Methods}

2.1. Cell Cultures. GT1-7 cells are from a mouse hypothalamic tumor cell line and release GnRH [11]. The GT1-7 cells used in the present study were offered by Professor Kyungjin Kim from Seoul National University (Seoul, Republic of Korea), and their use was approved by Dr. Pamela L. Mellon from University of California (San Diego, California, USA). GH3 cells are from a rat pituitary tumor cell line and release $\mathrm{GH}$. The GH3 cells used in the present study were provided by the Korean Cell Line Bank (Seoul, Republic of Korea). The GT1-7 cells were cultured in Dulbecco's Modified Eagle's Medium (DMEM, Gibco, Carlsbad, California, USA) and supplemented with $10 \%$ fetal bovine serum (FBS, Gibco) and $1 \%$ pen/strep antibiotics (Gibco). The GH3 cells were cultured in DMEM with Nutrient Mixture F-12 (DMEM/F-12, SigmaAldrich, St. Louis, Missouri, USA) supplemented with $10 \%$ FBS (Gibco) and 1\% pen/strep antibiotics (Gibco). The cells were plated in $150 \mathrm{~mm}$ cell culture dishes and grown in an incubator at $5 \% \mathrm{CO}_{2}$ and $37^{\circ} \mathrm{C}$.

2.2. Preparation of the Plant Extract. The cortex of Phellodendron amurense (Huang Bai) and the rhizome of Anemarrhena asphodeloides (Zhi Mu) were imported from China, whereas the spica of Prunella vulgaris (Xia Ku Cao) and the fruits of Hordeum vulgare (Mai Ya) were collected in Korea (Kyung Hee Herb Pharm., Seoul, Republic of Korea). Each dried plant was ground to a size $<5 \mathrm{~mm}$, and $30 \mathrm{~g}$ of each plant particle was extracted with $300 \mathrm{~mL}$ of distilled water (DW) at $100^{\circ} \mathrm{C}$ for 3 hours using a reflux heater (Changshin Science, Seoul, Republic of Korea). The extracted fluid was filtrated with filter paper (Hyundai Micro Co., Seoul, Republic of Korea), and the remaining fluid was evaporated to $<150 \mathrm{~mL}$ with a rotary evaporator (Sunileyela Co., Gyeonggi, Republic of Korea) and lyophilized with a freeze-dryer $\left(\mathrm{Operon}^{\mathrm{TM}}\right.$, Seoul, Republic of Korea). The powders were stored at $-20^{\circ} \mathrm{C}$.

The yields of the freeze-dried Huang Bai, Zhi Mu, Xia $\mathrm{Ku} \mathrm{Cao}$, and Mai Ya were approximately $10.40 \%, 38.07 \%$, $6.60 \%$, and $10.40 \%$, respectively. The Mai Ya extract was not fully dissolved in distilled water; therefore, the Mai Ya extract was dissolved in dimethyl sulfoxide (DMSO; Sigma-Aldrich, D8418), whereas the other three plant extracts were dissolved in DW.

2.3. MTT Assay. To assess cytotoxicity, the GT1-7 cells (1 $\times 10^{4}$ cells/well) [12] and the GH3 cells $\left(2 \times 10^{4}\right.$ cells/well $)$ [13] were seeded in 96-well cell culture plates and then grown in an incubator for 24 hours. The GT1-7 and GH3 cells were incubated with either DW, DMSO, or 30, 100, or $300 \mu \mathrm{g} / \mathrm{mL}$ of each plant extract solution in serum-free media (SFM) for 24 hours. Then, the treatment solutions were replaced with $100 \mu \mathrm{L}$ of a 3-(4,5-dimethylthiazol-2-yl)2,5-diphenyltetrazolium bromide (MTT) solution (SigmaAldrich, M5655). Following an incubation period of 1 hour, $100 \mu \mathrm{L}$ of DMSO was added to the plates and they were shaken for 10 minutes. The optical densities were measured at $570 \mathrm{~nm}$.

2.4. RT-PCR. To assess the quantity of messenger ribonucleic acid (mRNA), the GT1-7 cells $\left(5 \times 10^{5}\right.$ cells/well) $[14]$ and the GH3 cells $\left(1 \times 10^{6}\right.$ cells/well) [15] were seeded in $60 \mathrm{~mm}$ cell culture dishes with SFM and incubated overnight. The GT1-7 cells were incubated with DW, 10 nM estradiol (SigmaAldrich, E2758) [12], or noncytotoxic concentrations of each plant extract solution in SFM for 24 hours, whereas GH3 cells were incubated with DW and noncytotoxic concentrations of the plant extract solutions in SFM for 24 hours.

The total quantities of ribonucleic acid (RNA) from these two cell lines were isolated using the QIAzol ${ }^{\circledR}$ reagent (Qiagen, Venlo, Netherlands) and first-strand complementary deoxyribonucleic acid (cDNA) was synthesized using $1 \mu \mathrm{g}$ of RNA as a template in a SimpliAmp ${ }^{\text {тM }}$ Thermal Cycler (Applied Biosystems, Waltham, Massachusetts, USA) with a High Capacity cDNA Reverse Transcription Kit (Applied Biosystems) according to the manufacturer's protocols. A quantitative reverse transcription polymerase chain reaction (qRT-PCR) analysis was performed with the cDNA and primers (Table 1) using SYBR ${ }^{\circledast}$ Green Real-Time PCR Master Mix (Applied Biosystems) on a StepOnePlus ${ }^{\text {Tw }}$ Real-Time PCR System (Applied Biosystems). Each qRT-PCR was performed in triplicate.

2.5. Western Blot. To assess the quantity of protein level, the GT1-7 cells $\left(5 \times 10^{5}\right.$ cells/well) [14] and the GH3 cells $\left(1 \times 10^{6}\right.$ cells/well) [15] were seeded in $60 \mathrm{~mm}$ cell culture dishes with SFM and incubated overnight. The GT1-7 cells and the GH3 cells were incubated with DW or noncytotoxic concentrations of each plant extract solution in SFM for 24 hours. 
TABLE 1: Specific primers for the qRT-PCR analysis.

\begin{tabular}{|c|c|c|}
\hline Gene & & Sequence \\
\hline \multirow{2}{*}{ GAPDH } & F primer & $5^{\prime}$-TGGCCTCCAAGGAGTAAGAAAC-3' \\
\hline & $\mathrm{R}$ primer & $5^{\prime}$-CAGCAACTGAGGGCCTCTCT-3' \\
\hline \multirow{2}{*}{ GnRH } & F primer & $5^{\prime}$-CTACTGCTGACTGTGTGTTTG-3' \\
\hline & $\mathrm{R}$ primer & $5^{\prime}$-СATCTTCTTCTGCCTGGCTTC-3' \\
\hline \multirow{2}{*}{$\mathrm{GH}$} & F primer & $5^{\prime}$-ACTCCCTGGCTCCTGACCTT-3' \\
\hline & R primer & $5^{\prime}$-GGATGAGCAGCAGCGAGAA-3' \\
\hline
\end{tabular}

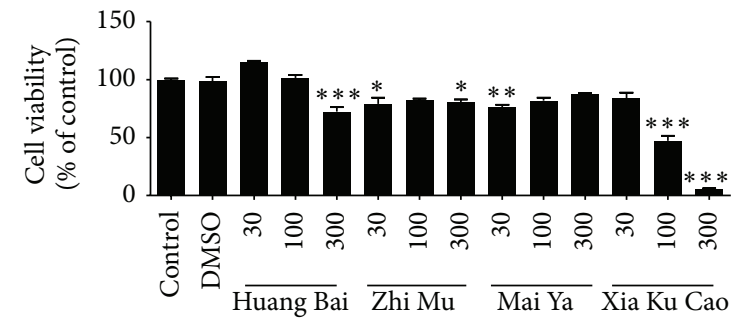

(a)

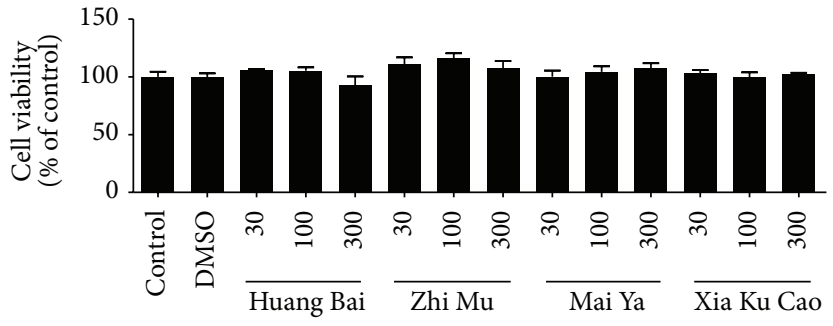

(b)

Figure 1: Cell viability of GT1-7 (a) and GH3 (b) cells was analyzed as reduction of MTT to formazan. All results were expressed as the percentage of optical density of control (distilled water treated cells). The results ran in triplicate and expressed as mean \pm standard deviation. Statistical analysis of Huang Bai, Zhi Mu, and Xia Ku Cao was compared to control, and that of Mai Ya was compared to DMSO: ${ }^{*} P<0.05$, ${ }^{* *} P<0.01$, and ${ }^{* * *} P<0.001$.

The cells were lysed in a lysis buffer containing $50 \mathrm{mM}$ HEPES (pH 7.5), 150 mM NaCl, 10\% glycerol, 1\% Triton X100, $1 \mathrm{mM}$ PMSF, $1 \mathrm{mM}$ EGTA, $1.5 \mathrm{mM} \mathrm{MgCl} 2 \cdot 6 \mathrm{H}_{2} \mathrm{O}, 1 \mathrm{mM}$ sodium orthovanadate, and $100 \mathrm{mM}$ sodium fluoride. Protein content was measured using a Bio-Rad colorimetric protein assay kit (Bio-Rad). Protein of $30 \mu \mathrm{g}$ was separated on SDSpolyacrylamide gels and transferred onto a nitrocellulose membrane. Goat GH antibody $(1: 1000$, Santa Cruz Biotech, California, USA), rabbit GnRH antibody (1:1000, Santa Cruz Biotech, California, USA), and mouse anti- $\beta$-actin antibody (1:5000, Santa Cruz Biotech, California, USA) were used as primary antibodies. Horseradish peroxidaseconjugated anti-goat antibody for GH (1:1000, Millipore, Darmstadt, Germany) was used as secondary antibody. Horseradish peroxidase-conjugated anti-rabbit antibody for GnRH (1:1000, Millipore) was used as secondary antibody. Horseradish peroxidase-conjugated anti-mouse antibody for $\beta$-actin (1:1000, Santa Cruz) was used as secondary antibody. Band detection was performed using the enhanced chemiluminescence (ECL) detection system (Amersham Pharmacia Biotech $\mathrm{GmbH}$, Freiburg, Germany). To compare relative expression of proteins, detected bands were calculated densitometrically using Image J (National Institutes of Health, Bethesda, Maryland, USA). Immunoreactive band optical density using $\mathrm{GnRH}$ and $\mathrm{GH}$ antibody was divided by optical density using $\beta$-actin antibody.

2.6. Statistical Analysis. MTT assay and RT-PCR data were expressed as mean \pm standard deviation and western blot data were expressed as mean \pm standard error. Data were analyzed with Student's $t$-tests (GraphPad Software Inc., La
Jolla, California, USA). A $P$ value $<0.05$ was considered to indicate statistical significance.

\section{Results}

3.1. Cytotoxicity. The cell viabilities of the GT1-7 and GH3 cell lines were compared with those of a DW group (Huang $\mathrm{Bai}, \mathrm{Zhi} \mathrm{Mu}$, and Xia $\mathrm{Ku} \mathrm{Cao}$ ) or a DMSO group (Mai Ya) (Figure 1). The maximum noncytotoxic treatment concentrations of Huang Bai, Zhi Mu, Mai Ya, and Xia Ku Cao in GT1-7 were $30 \mu \mathrm{g} / \mathrm{mL}, 100 \mu \mathrm{g} / \mathrm{mL}, 100 \mu \mathrm{g} / \mathrm{mL}$, and $300 \mu \mathrm{g} / \mathrm{mL}$, respectively. There was only a slight difference between the 100 and $300 \mu \mathrm{g} / \mathrm{mL}$ concentrations of $\mathrm{Zhi} \mathrm{Mu}$; therefore, the final treatment concentrations for the extracts in the GT1-7 cells were $30 \mu \mathrm{g} / \mathrm{mL}, 300 \mu \mathrm{g} / \mathrm{mL}, 100 \mu \mathrm{g} / \mathrm{mL}$, and $300 \mu \mathrm{g} / \mathrm{mL}$, respectively. The maximum noncytotoxic treatment concentrations of Huang Bai, Zhi Mu, Mai Ya, and $\mathrm{Xia} \mathrm{Ku} \mathrm{Cao}$ in the $\mathrm{GH} 3$ cells were all $300 \mu \mathrm{g} / \mathrm{mL}$; therefore, the final treatment concentration for all plant extracts in $\mathrm{GH} 3$ cells was $300 \mu \mathrm{g} / \mathrm{mL}$.

3.2. GnRH and GH mRNA Expression. The expression of GnRH mRNA in the GT1-7 cells and expression of GH mRNA in the GH3 cells were compared with those in a DW group (Figures 2 and 3). The expression of $\mathrm{GnRH}$ mRNA changed by $69 \%, 46 \%, 78 \%, 70 \%$, and $58 \%$ following treatment with estradiol, Huang Bai, Zhi Mu, Mai Ya, and Xia $\mathrm{Ku}$ Cao, respectively. The expression of GH mRNA changed by $129 \%, 102 \%, 120 \%$, and $80 \%$ following treatment with Huang Bai, Zhi Mu, Mai Ya, and Xia Ku Cao, respectively. 


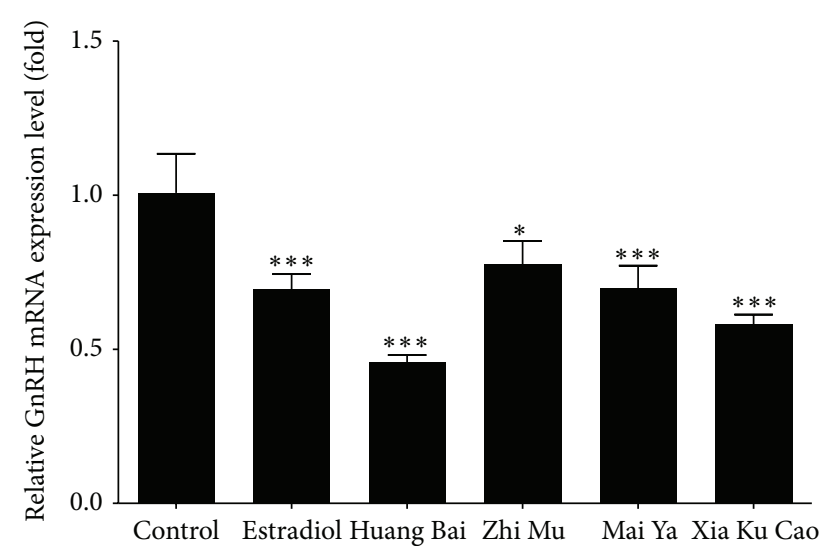

FIGURE 2: GT1-7 cells were treated with either distilled water (control), $10 \mathrm{nM}$ of estradiol, $100 \mu \mathrm{g} / \mathrm{mL}$ of Huang Bai, $300 \mu \mathrm{g} / \mathrm{mL}$ of Zhi Mu, $300 \mu \mathrm{g} / \mathrm{mL}$ of Mai Ya, or $30 \mu \mathrm{g} / \mathrm{mL}$ of Xia Ku Cao for 24 hours. Total RNAs were extracted and quantitative RT-PCR was performed with GnRH mRNA amplifying primers. The results ran in triplicate and expressed as mean \pm standard deviation. Statistical analysis: ${ }^{*} P<0.05,{ }^{* * *} P<0.001$ as compared to control.

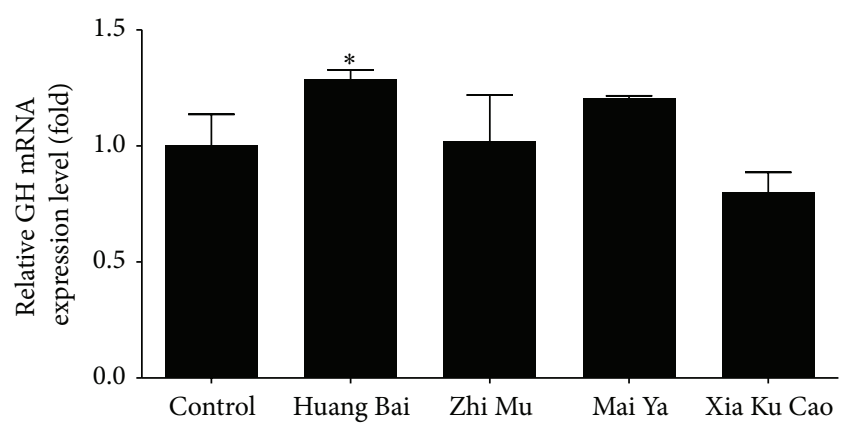

FIGURE 3: GH3 cells were treated with either distilled water (control), $300 \mu \mathrm{g} / \mathrm{mL}$ of Huang Bai, $300 \mu \mathrm{g} / \mathrm{mL}$ of Zhi Mu, $300 \mu \mathrm{g} / \mathrm{mL}$ of Mai Ya, or $300 \mu \mathrm{g} / \mathrm{mL}$ of Xia Ku Cao for 24 hours. Total RNAs were extracted and quantitative RT-PCR was performed with GH mRNA amplifying primers. The results ran in triplicate and expressed as mean \pm standard deviation. Statistical analysis: ${ }^{*} P<0.05$ as compared to control.

Four herbs inhibited GnRH mRNA expression in GT1-7 cells; however, Huang Bai promoted GH mRNA expression in GH3 cells.

3.3. GnRH and GH Protein Expression. Relative optical densities using GnRH antibody of control, Huang Bai, Zhi Mu, Mai $\mathrm{Ya}$, and Xia Ku Cao were $1.88 \pm 0.31,1.09 \pm 0.39,1.17 \pm 0.38$, $1.05 \pm 0.26$, and $0.68 \pm 0.29$, respectively (Figure 4 ). Relative optical densities using GH antibody of control, Huang Bai, Zhi Mu, Mai Ya, and Xia Ku Cao were $0.96 \pm 0.18,2.36 \pm 0.15$, $1.60 \pm 0.40,1.11 \pm 0.24$, and $1.12 \pm 0.08$, respectively (Figure 5). Xia Ku Cao inhibited GnRH protein extracts in GT1-7 cells and Huang Bai promoted GH protein extracts in GH3 cells.

\section{Discussion}

The qRT-PCR measurements showed that the water extracts of Huang Bai, Zhi Mu, Mai Ya, and Xia Ku Cao significantly inhibited the GnRH mRNA expression in GT1-7 cells. Of these herbs, Huang Bai showed greater suppressive effect on GnRH mRNA expression than estradiol $(P<0.05)$. Although estradiol is known to bidirectionally regulate the $\mathrm{GnRH}$ secreting neuronal function according to the ovulatory cycle in females, it also decreases GnRH gene expression in GT1-7 cells [16]. The GT1-7 cell line is derived from a transgenic mouse hypothalamic tumor and has many of the characteristics of GnRH secreting neurons [11]. Huang Bai and the other three herbs act directly on GnRH neurons which is pivotal for gonadotropin synthesis and release in pituitary. The downregulation of GnRH mRNA mechanism of the four herbs could be established by further receptor signaling study. Different to GnRH mRNA expression, Xia Ku Cao only decreased GnRH protein extracts from GT1-7 cells. Discordance of the results will be studied by further protein synthesis or activation study.

In the present study, the exposure of $\mathrm{GH} 3$ cells to the extract of Huang Bai increased the expression of GH mRNA and also increased the expression GH protein. The GH3 cell line is rat pituitary adenoma cell which produces $\mathrm{GH}$ and prolactin [17]. Huang Bai also acts directly on GH neurons as well as GnRH neurons. Further studies are necessary in order to decide if increased GH mRNA and protein expression is due to the increase in transcription or stability of the mRNA and protein.

The findings of in vitro study suggest that Huang Bai directly inhibits $\mathrm{GnRH}$ gene expression in hypothalamus and promotes $\mathrm{GH}$ gene and protein expression in pituitary, therefore enhancing possibility of direct actions on $\mathrm{GnRH}$ and GH neurosecretory system in vivo. Dose- or timedependent analysis and further in vivo studies are needed for clear efficacy of Huang Bai on GnRH and GH system.

Previous studies have demonstrated that the bark of Huang Bai has antidiabetic [18], anti-heat stress [19], antiinflammatory [20], antimicrobial [21, 22], and neuroprotective [23] effects and that the spike of Xia $\mathrm{Ku}$ Cao exhibits antitumor [24, 25] and immunosuppressive [26] activities. Similarly, the rhizome of $\mathrm{Zhi} \mathrm{Mu}$ possesses antidiabetic, antiinflammatory, anticoagulatory, antihypertensive, antitumor, antioxidative, antimicrobial, antiviral, antiosteoporosis, antiskin aging, and neuroprotective [27] effects; additionally, the fruit of Mai Ya exerts antihyperprolactinemia activity [28]. The results of our study newly suggest maturation-inhibiting effect of these four herbs and growth-promoting effect of Huang Bai.

\section{Conflict of Interests}

The authors declare no conflict of interests.

\section{Acknowledgments}

This study was supported by a grant of the Korean Health Technology R\&D Project, Ministry of Health \& Welfare, 


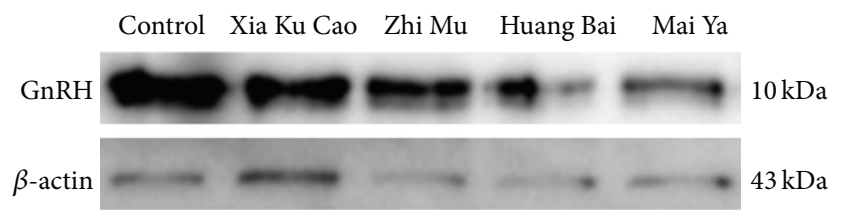

(a)

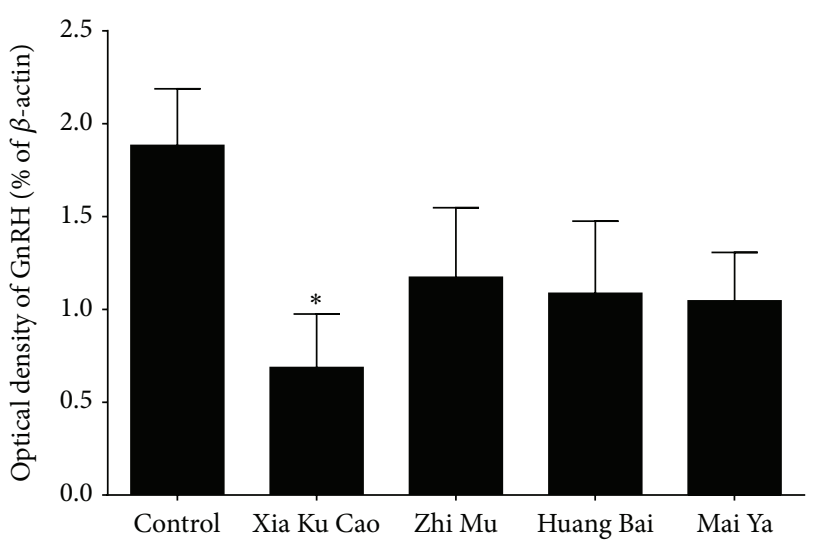

(b)

Figure 4: (a) GT1-7 cells were precultured for 24 hours in serum-free media and cultured with distilled water (control), $30 \mu \mathrm{g} / \mathrm{mL}$ of Xia $\mathrm{Ku}$ Cao, $300 \mu \mathrm{g} / \mathrm{mL}$ of Zhi Mu, $100 \mu \mathrm{g} / \mathrm{mL}$ of Huang Bai, or $300 \mu \mathrm{g} / \mathrm{mL}$ of Mai Ya. The 24-hour treated cells were lysed and subjected to SDS-PAGE/immunoblotting analysis using anti-GnRH and anti-actin antibodies. Protein bands are representative of three independent experiments. (b) Each band optical density was digitized by NIH Image J. Digitized Analysis of band optical intensity evaluated by adjusted volume. Results are expressed as mean \pm standard error of triplicate data. ${ }^{*} P<0.05$ as compared with control.

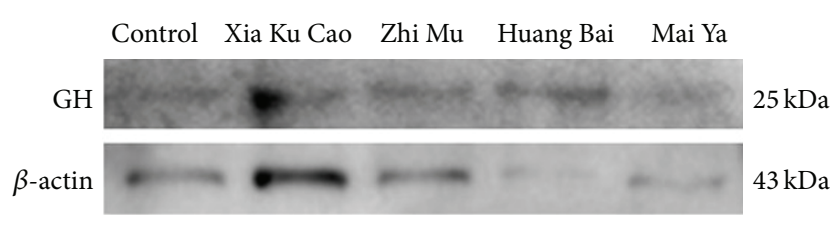

(a)

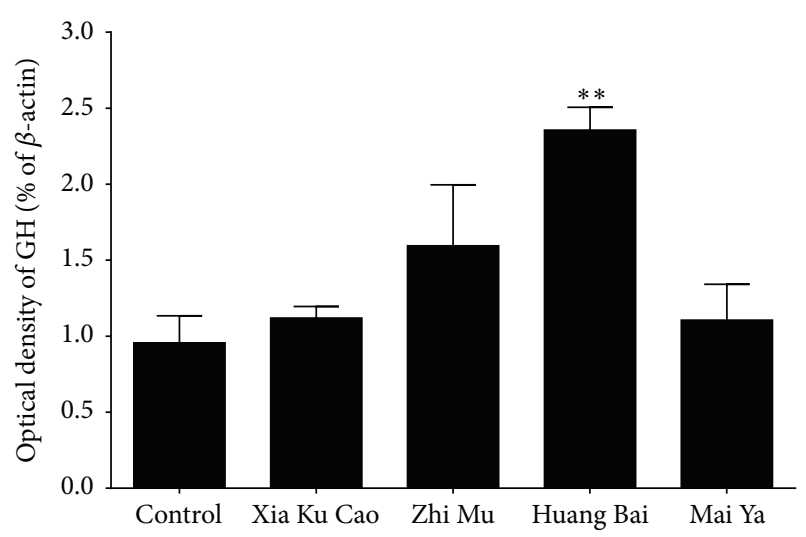

(b)

FIgURE 5: (a) GH3 cells were precultured for 24 hours in serum-free media and cultured with distilled water (control), $30 \mu \mathrm{g} / \mathrm{mL}$ of Xia $\mathrm{Ku}$ Cao, $300 \mu \mathrm{g} / \mathrm{mL}$ of Zhi Mu, $100 \mu \mathrm{g} / \mathrm{mL}$ of Huang Bai, or $300 \mu \mathrm{g} / \mathrm{mL}$ of Mai Ya. The 24-hour treated cells were lysed and subjected to SDS-PAGE/immunoblotting analysis using anti-GnRH and anti-actin antibodies. Protein bands are representative of three independent experiments. (b) Each band optical density was digitized by NIH Image J. Digitized Analysis of band optical intensity evaluated by adjusted volume. Results are expressed as mean \pm standard error of triplicate data. ${ }^{* *} P<0.01$ as compared with control.

Republic of Korea (HI14C0976). The authors thank Professor Kyungjin Kim (Seoul National University, Seoul, Republic of Korea) and Dr. Pamela L. Mellon (University of California, San Diego, California, USA) for the kind donation of GT1-7 neurons and also acknowledge Korean Cell Line Bank (Seoul, Republic of Korea) for the provision of GH3 neurons.

\section{References}

[1] C.-H. Yu, P.-H. Liu, Y.-H. Van, A. S.-Y. Lien, T.-P. Huang, and H.-R. Yen, "Traditional Chinese medicine for idiopathic precocious puberty: a hospital-based retrospective observational study," Complementary Therapies in Medicine, vol. 22, no. 2, pp. 258-265, 2014.
[2] R. Huang, Y. H. Wang, and J. Yu, "Exploration of regularity of TCM syndrome differentiation and treatment of precocious puberty," China Journal of Traditional Chinese Medicine and Pharmacy, vol. 26, no. 2, pp. 347-349, 2011.

[3] D. Cai and W. Zhang, "Regulative actions of the Chinese drugs for tonifying the kidney on gene expression of the hypothalamic GnRH, pituitary FSH, LH and osteoblastic BGP," Journal of Traditional Chinese Medicine, vol. 25, no. 1, pp. 58-61, 2005.

[4] D.-P. Cai, B.-Y. Chen, W. Zhang, and P. Li, "Effects of Chinese herbal medicine on modulating the course of puberty development in children with precocious puberty," Zhong Xi Yi Jie He Xue Bao, vol. 4, no. 2, pp. 166-174, 2006.

[5] Y. Sun, G. N. Perry, J. Yu, B. Chen, and Z. Tian, "Effect of nourishing 'Yin'-removing 'Fire' Chinese herbal mixture on 
hypothalamic kisspeptin expression in female precocious rats," Journal of Ethnopharmacology, vol. 127, no. 2, pp. 274-279, 2010.

[6] Z. Tian, H. Zhao, Y. Sun, D. Cai, and B. Chen, "Evaluation of the true precocious puberty rats induced by neonatal administration of Danazol: therapeutic effects of nourishing 'Yin'removing 'Fire' Chinese herb mixture," Reproductive Biology and Endocrinology, vol. 3, article 38, 2005.

[7] L. Z. Yang, X. J. Zhang, Y. Zheng, and L. J. Gao, "Effect of Zhizao granule on BGP of premature rats induced by NMA," Information on Traditional Chinese Medicine, vol. 31, no. 2, pp. 52-54, 2014.

[8] L.-Y. Sun, Q.-S. Yu, X.-Y. Hu et al., “The impact on gonadal development of precocious puberty rats by GuizhenDihuangYin," Information on Traditional Chinese Medicine, vol. 30, no. 1, pp. 21-23, 2013.

[9] Y. Zeng, Experimental Study on the Inhibition on the HPG Axis of Pubertal Rats by Arnebia, Chongqing Medical University, Chongqing, China, 2007.

[10] L. L. Song, The Effect of Lithospermum Extracts Treatment on Experimental True Precocious Puberty, Chongqing Medical University, Chongqing, China, 2006.

[11] P. L. Mellon, J. J. Windle, P. C. Goldsmith, C. A. Padula, J. L. Roberts, and R. I. Weiner, "Immortalization of hypothalamic GnRH neurons by genetically targeted tumorigenesis," Neuron, vol. 5, no. 1, pp. 1-10, 1990.

[12] J. Bowe, X. F. Li, D. Sugden, J. A. Katzenellenbogen, B. S. Katzenellenbogen, and K. T. O'Byrne, "The effects of the phytoestrogen, coumestrol, on gonadotropin-releasing hormone (GnRH) mRNA expression in GT1-7 GnRH neurones," Journal of Neuroendocrinology, vol. 15, no. 2, pp. 105-108, 2003.

[13] G. Liao, J. Zhou, H. Wang et al., "The cell toxicity effect of secalonic acid D on GH3 cells and the related mechanisms," Oncology Reports, vol. 23, no. 2, pp. 387-395, 2010.

[14] R. Sasson, R. K. Dearth, R. S. White, P. E. Chappell, and P. L. Mellon, "Orexin A induces GnRH gene expression and secretion from GT1-7 hypothalamic GnRH neurons," Neuroendocrinology, vol. 84, no. 6, pp. 353-363, 2007.

[15] A. M. Nanzer, S. Khalaf, A. M. Mozid et al., "Ghrelin exerts a proliferative effect on a rat pituitary somatotroph cell line via the mitogen-activated protein kinase pathway," European Journal of Endocrinology, vol. 151, no. 2, pp. 233-240, 2004.

[16] Y. Ng, A. Wolfe, H. J. Novaira, and S. Radovick, "Estrogen regulation of gene expression in GnRH neurons," Molecular and Cellular Endocrinology, vol. 303, no. 1-2, pp. 25-33, 2009.

[17] L. Langouche, M. Roudbaraki, K. Pals, and C. Denef, "Stimulation of intracellular free calcium in GH3 cells by gamma3melanocyte-stimulating hormone. Involvement of a novel melanocortin receptor?" Endocrinology, vol. 142, no. 1, pp. 257266, 2001.

[18] H.-J. Kim, M.-K. Kong, and Y.-C. Kim, "Beneficial effects of Phellodendri Cortex extract on hyperglycemia and diabetic nephropathy in streptozotocin-induced diabetic rats," Journal of Biochemistry and Molecular Biology, vol. 41, no. 10, pp. 710-715, 2008.

[19] X.-Y. Zhu, G.-L. Cheng, F.-H. Liu et al., “Taguchi approach for anti-heat stress prescription compatibility in mice spleen lymphocytes in Vitro," Archives of Pharmacal Research, vol. 34, no. 7, pp. 1125-1133, 2011.

[20] Y. Y. Choi, M. H. Kim, J. M. Han et al., "The anti-inflammatory potential of Cortex Phellodendron in vivo and in vitro: downregulation of $\mathrm{NO}$ and iNOS through suppression of NF- $\kappa \mathrm{B}$ and
MAPK activation," International Immunopharmacology, vol. 19, no. 2, pp. 214-220, 2014.

[21] C. J. Seneviratne, R. W. K. Wong, and L. P. Samaranayake, "Potent anti-microbial activity of traditional Chinese medicine herbs against Candida species," Mycoses, vol. 51, no. 1, pp. 30-34, 2008.

[22] R. W. K. Wong, U. Hägg, L. Samaranayake, M. K. Z. Yuen, C. J. Seneviratne, and R. Kao, "Antimicrobial activity of Chinese medicine herbs against common bacteria in oral biofilm. A pilot study," International Journal of Oral and Maxillofacial Surgery, vol. 39, no. 6, pp. 599-605, 2010.

[23] Y.-F. Xian, Z.-X. Lin, S.-P. Ip, Z.-R. Su, J.-N. Chen, and X.-P. Lai, "Comparison the neuropreotective effect of Cortex Phellodendri chinensis and Cortex Phellodendri amurensis against betaamyloid-induced neurotoxicity in PC12 cells," Phytomedicine, vol. 20, no. 2, pp. 187-193, 2013.

[24] W. Lin, L. Zheng, Q. Zhuang et al., "Spica prunellae promotes cancer cell apoptosis, inhibits cell proliferation and tumor angiogenesis in a mouse model of colorectal cancer via suppression of stat3 pathway," BMC Complementary and Alternative Medicine, vol. 13, article 144, 2013.

[25] X. Mao, G. Wang, W. Zhang, and S. Li, "A study on inhibitory effect of Spica prunellae extract on T lymphoma cell EL-4 tumour," African Journal of Traditional, Complementary and Alternative Medicines, vol. 10, no. 5, pp. 318-324, 2013.

[26] H.-X. Sun, F. Qin, and Y.-J. Pan, "In vitro and in vivo immunosuppressive activity of Spica Prunellae ethanol extract on the immune responses in mice," Journal of Ethnopharmacology, vol. 101, no. 1-3, pp. 31-36, 2005.

[27] Y. Wang, Y. Dan, D. Yang et al., "The genus Anemarrhena Bunge: a review on ethnopharmacology, phytochemistry and pharmacology," Journal of Ethnopharmacology, vol. 153, no. 1, pp. 42-60, 2014.

[28] X. Wang, L. Ma, E. Zhang et al., "Water extract of Fructus hordei germinatus shows antihyperprolactinemia activity via dopamine D2 receptor," Evidence-Based Complementary and Alternative Medicine, vol. 2014, Article ID 579054, 7 pages, 2014. 


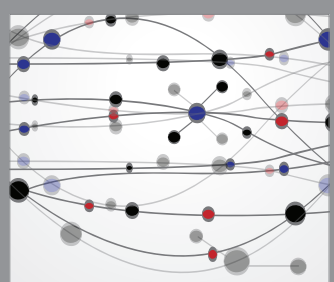

The Scientific World Journal
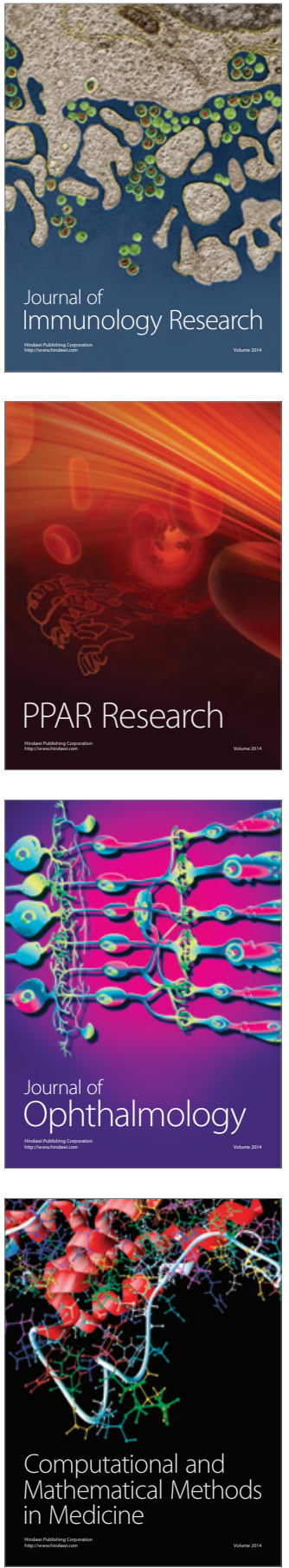

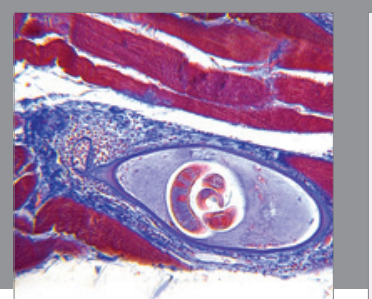

Gastroenterology Research and Practice

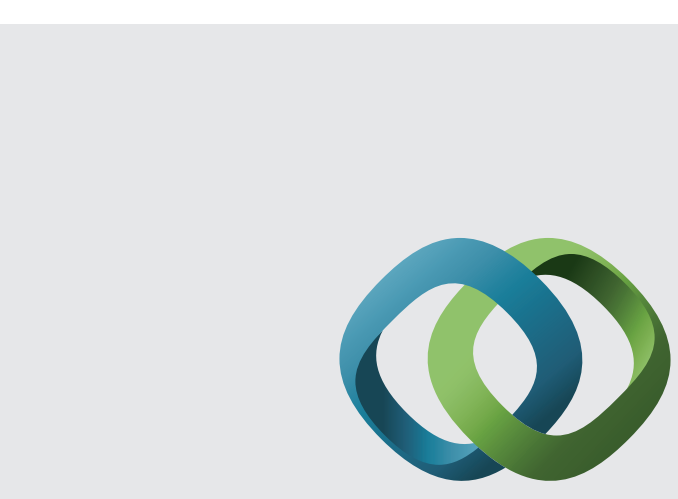

\section{Hindawi}

Submit your manuscripts at

http://www.hindawi.com
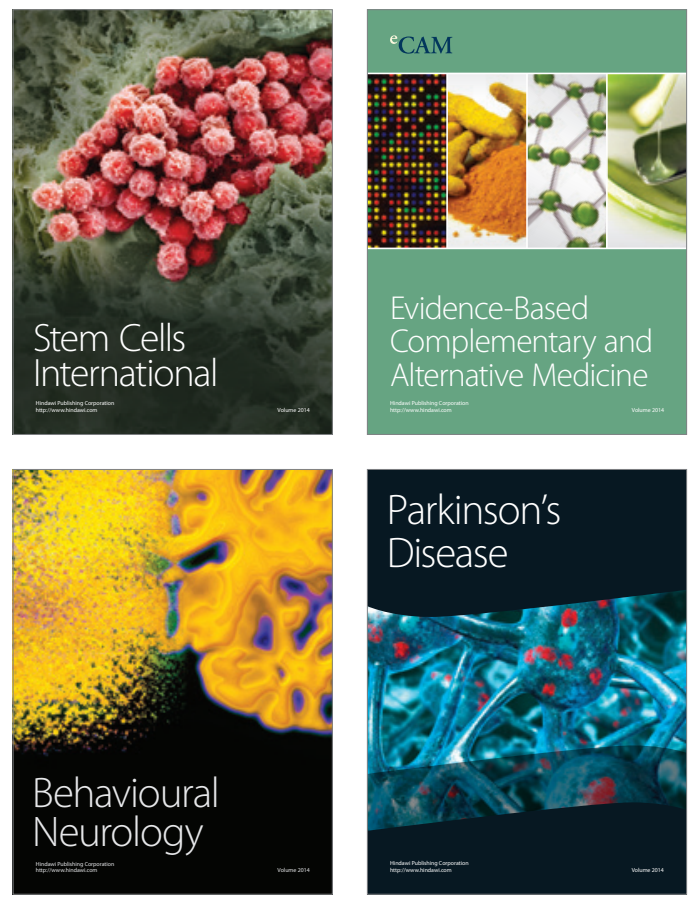
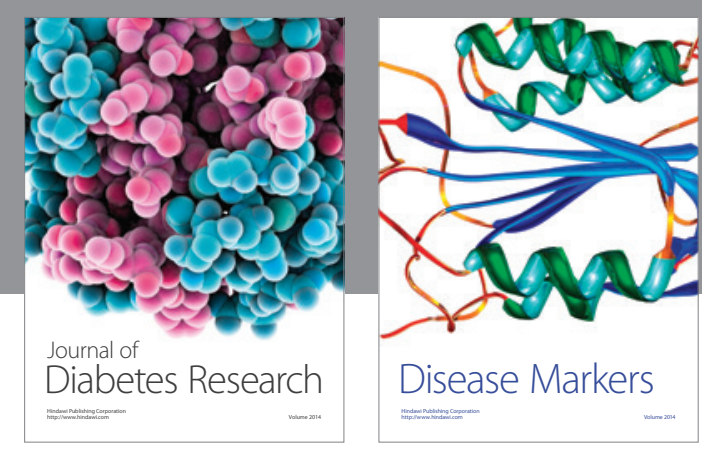

Disease Markers
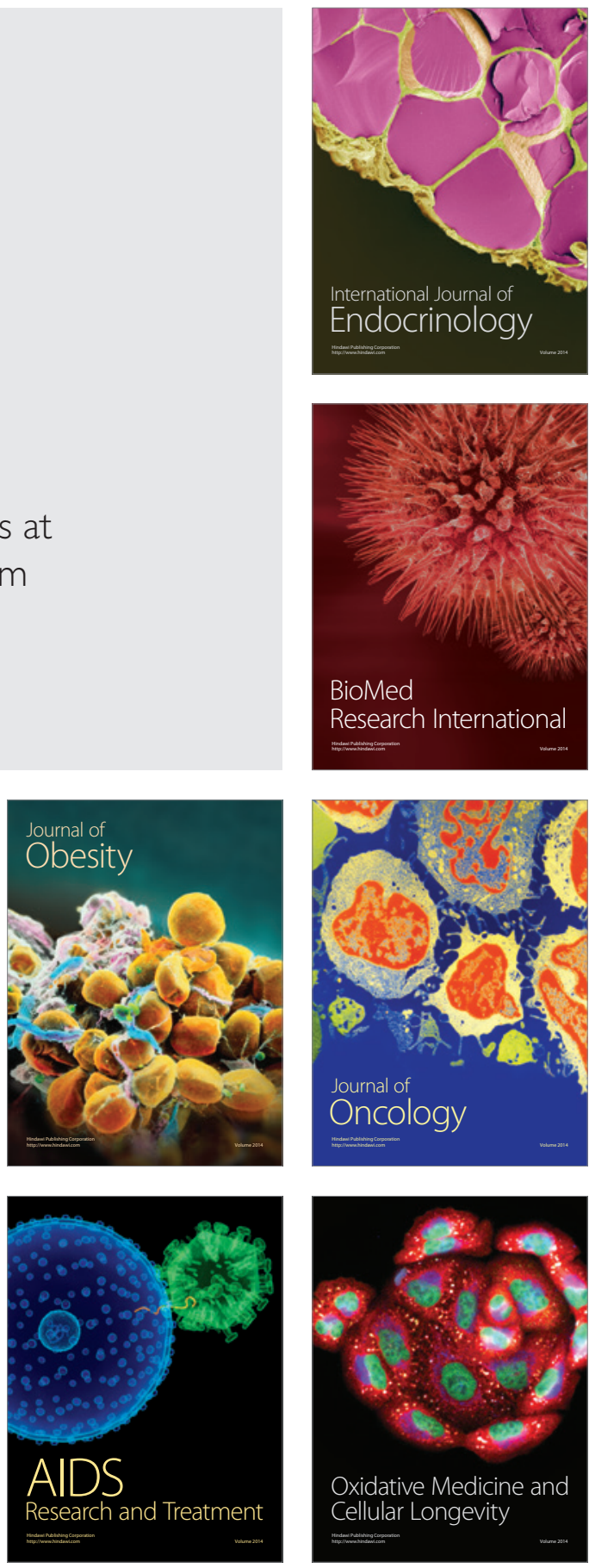